\title{
A Regional Climate Study of Heat Waves over the Iberian Peninsula
}

\author{
Hari Prasad Dasari1 ${ }^{*}$, Isaac Pozo², Francisco Ferri-Yáñezz,3,4, Miguel B. Araújo 2,3,4 \\ ${ }^{1}$ Centro de Geofisica de Évora, University of Évora, Évora, Portugal \\ ${ }^{2}$ Museo Nacional de Ciencias Naturales, CSIC, Madrid, Spain \\ ${ }^{3}$ Centro de Biodiversidade e Recursos Genéticos (InBIO-CIBIO), University of Évora, Évora, Portugal \\ ${ }^{4}$ Imperial College London, Silwood Park Campus, Berkshire, UK \\ Email: hari@uevora.pt, ipozo@mncn.csic.es, francisco ferri@mncn.csic.es, maraujo@mncn.csic.es
}

Received 2 September 2014; revised 25 October 2014; accepted 17 November 2014

Academic Editor: Qiang Zhang, Sun Yat-sen University, China

Copyright (C) 2014 by authors and Scientific Research Publishing Inc.

This work is licensed under the Creative Commons Attribution International License (CC BY).

http://creativecommons.org/licenses/by/4.0/

(c) (i) Open Access

\begin{abstract}
We present a regional climate simulation for the Iberian Peninsula for a 60-year period (19502009) using the WRF-ARW model with a focus on the simulation of summer maximum temperatures and associated extreme heat waves. The WRF model was designed at a $5 \mathbf{~ k m}$ horizontal resolution on a 5-month (May-September) seasonal scale, for every year, during the study period with initial/boundary conditions derived from NCEP 2.5 degree reanalysis. The comparison of simulated mean summer seasonal maximums and mean maximums of June, July, and August months with the corresponding E-OBS data sets indicates that the model is able to characterize the spatial variation of magnitudes of temperature change over the Iberian Peninsula. The mean extreme heat wave conditions during the climate period 1950-2009 are well simulated and match the observations well. The regional scale simulations clearly show the propagation of intense heat waves from the south west to north east of Iberia. The WRF-ARW model also simulated well the general trend of increase in heat waves over most parts of the Iberian Peninsula during the study period 1950-2009. The characteristics of the most severe heat waves years 2003 and 2006 are also well simulated by the model.
\end{abstract}

\section{Keywords}

Downscaling, Heat Waves, Iberian Peninsula, Regional Climate Modelling

${ }^{*}$ Corresponding author. 


\section{Introduction}

The Iberian Peninsula falls in the transition zone of tropical and extra tropical climates with more than $80 \%$ of days of clear sky and sunshine. The region is usually influenced by the cold temperatures of the Atlantic Ocean and the warm temperatures over the Mediterranean Sea and the Sahara desert. Because of the peculiar geography of this region, there is a marked north-south climate gradient as well as a gradient of increased diurnal and seasonal thermal variation from the coastal areas to the centre of the Peninsula. High mountain ridges in the northern limits of the Peninsula also influence the regional weather and climate, while acting as barrier between northern and southern Europe.

Several studies have reported an increase in the frequency of heat waves in Europe and models forecast even higher frequency by the end of the $21^{\text {st }}$ century [1] [2]. Many reasons have been proposed for such increase in the frequency of heat waves in Europe. One reason is related to the general warming due to increased green house gases from anthropogenic activities [3]. Climate model projections indicate that increases in annual mean temperatures with higher warming in the winter over northern Europe and in the summer over the Mediterranean area [4]. Tebaldi et al., [5] reported that maximum summer temperatures in southern and central Europe are likely to increase more than mean temperatures. Another reason is the movement of anti cyclonic weather regimes to form heat waves in Europe. Cassou et al. [6] reported that the synoptic Rossby wave trains from tropical Atlantic sea surface temperatures are favourable conditions to form heat and drought conditions over Europe. Della Marta et al. [7] reported that apart from the synoptic conditions the feedbacks from regional land surfaces act positively to amplify the summer maximum temperatures over Europe. Other factors like heat advection, cloud cover, radiation and moist convection also contribute to increasing summer temperatures [8]. The soilatmosphere feedbacks were studied during four severe summer seasons by Ficher et al. [9] [10]. It has been reported that dry soil promotes a positive feed-back mechanism of anticyclone conditions by reducing the moist convection, reducing clouds and increasing the solar energy at the surface thereby further increasing the heat fluxes and the Bowen ratio [11]. D’Andrea et al. [12] suggests that even though the soil moisture is a key factor in controlling summer mean temperatures there is little work done on the physical process involved in it. Vautard and Coauthorset [13] analysed the 10 hottest summers since 1948 revealing that hot summers can occur after normal or wet winter and spring conditions in the north and drier soils in Southern Europe.

High resolution Regional Climate Models (RCMs) with improved physics in respect of clouds, land surface, boundary layer diffusion and convection process have shown to be useful to simulate regional climate. The major advantage in using RCMs is the inclusion of regional effects of topography, coastlines, mountains, water bodies, and vegetation on the local climate [14]-[28]. The focus of this study is to simulate the extreme temperatures and heat wave conditions over the Iberian Peninsula using the WRF regional model [29] and evaluate it through hindcasting using available $20^{\text {th }}$ century climate data.

We chose this model because of its sophisticated physics for land-surface, planetary boundary layer, radiation and other atmospheric processes that are important to simulate regional and small-scale atmospheric processes affecting climate. The temperature patterns over the Iberian Peninsula, their long-term variability and the subregional variations, are simulated with a nested regional model at $5 \mathrm{~km}$ resolution along a 60-year period (19502009) for the summer seasons.

\section{Model and Data}

In this study we used the Advanced Research Weather Research and Forecasting (ARW) regional model [29] to simulate long-term temperatures over the Iberian Peninsula. The model uses non-hydrostatic compressible Navier-Stokes equations for the atmosphere in a terrain following sigma coordinate system. The model is highly flexible for choosing the domain region with multiple nested domains, physics and diffusion options. The model is configured with two-way interactive two-nested domains with horizontal grid resolutions of $75 \mathrm{~km}$ and $25 \mathrm{~km}$. One-way nesting is used in generating a $5 \mathrm{~km}$ resolution from the $25 \mathrm{~km}$ resolution result. The domain area and design of the three domains is presented in Figure 1. The model physics and other details are presented in Table 1. The outer domain covers the entire Europe and parts of the Atlantic Ocean, and Southern arctic. The inner domain with $5 \mathrm{~km}$ horizontal resolution covers the Iberian Peninsula alone. We used the National Centers for Environmental Prediction (NCEP) global analysis fields [30], available at 2.5 degree latitude/longitude resolution and at 6-hour interval, for initial atmospheric fields and the time varying boundary conditions. The model was integrated continuously for 5 months, starting at 00UTC of the $1^{\text {st }}$ of May for each year starting in 1950 and 


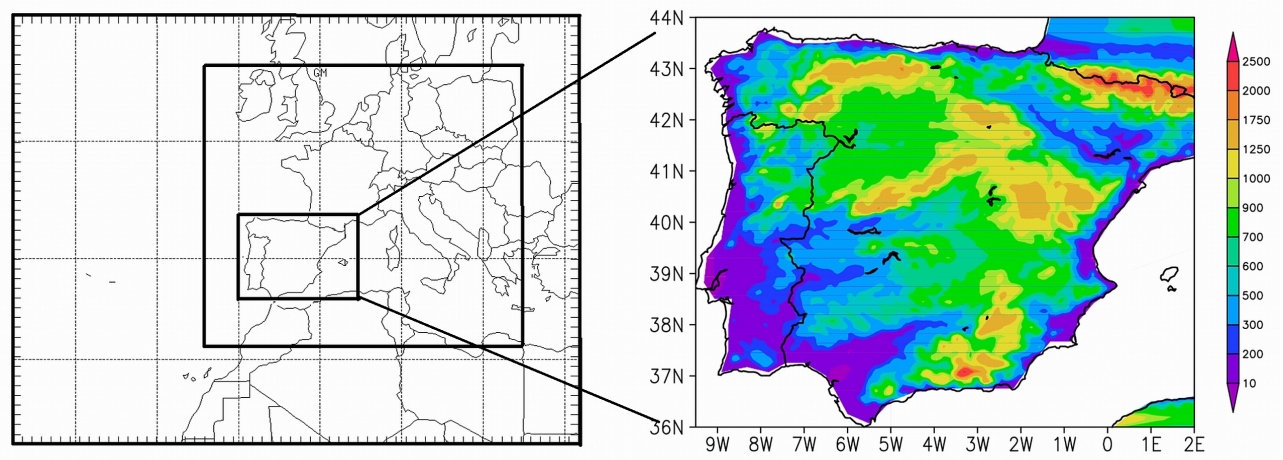

Figure 1. Model chosen domains with topography.

Table 1. Model details and configuration.

\begin{tabular}{|c|c|c|c|}
\hline Model Name & & NCEP/NCAR ARW & \\
\hline Model type & & Primitive equation, non-hydrostatic & \\
\hline Vertical resolution & & 30 sigma levels & \\
\hline Horizontal resolution & $75 \mathrm{~km}$ & $25 \mathrm{~km}$ & $5 \mathrm{~km}$ \\
\hline Domain of integration & $\begin{array}{l}38.5 \mathrm{~W}-30.83 \mathrm{E} \\
21.82 \mathrm{~N}-59.75 \mathrm{~N}\end{array}$ & $\begin{array}{l}13.585 \mathrm{~W}-24.8351 \mathrm{E} \\
31.7935 \mathrm{~N}-55.7455 \mathrm{~N}\end{array}$ & $\begin{array}{l}9.429 \mathrm{~W}-3.037 \mathrm{E} \\
35.947 \mathrm{~N}-43.98 \mathrm{~N}\end{array}$ \\
\hline Radiation scheme & & $\begin{array}{l}\text { CAM scheme for short wave radiation } \\
\text { CAM scheme for long wave radiation }\end{array}$ & \\
\hline Land-surface scheme & & Thermal diffusion scheme & \\
\hline Sea surface temperature & & Real sea surface temperatures & \\
\hline Convection scheme & & Grell-devenyi ensemble scheme & \\
\hline PBL scheme & & YSU scheme & \\
\hline Explicit moisture scheme & & WSM 3-class simple ice scheme & \\
\hline
\end{tabular}

continuing for the entire 6 decades (1950-2009). This procedure aimed at improving the knowledge of the temperature variations in the summer seasons (June, July and August) linked to extreme heat events over the Iberian Peninsula. The model outputs were generated at 1-hour intervals keeping in mind the need of high-resolution temporal data in several climate change impact studies, such as the case of biodiversity [31]. The first month results in all simulations were considered as a spin-up time and were not used for analysis. The daily maximum temperatures were computed from the 1-hour interval outputs. The model results for the whole 60-year period (1950 to 2009) were compared with E-OBS V7.0 [32] observations available at 0.25 degrees. It is important to note that no corrections for E-OBS datasets have been made and Soares et al., [33], reported deficiencies with this data source.

\section{Results and Discussion}

The results are presented in three sections. The first section focuses on 60-year mean values of maximum temperatures for summer season (JJA) and individual months of June, July and August, all of which are computed and analysed for both model and E-OBS. In this section we also focused on the variability of maximum temperatures for pre-industrial and post-industrial era based on the reference period (1961-1990). In the second section the mean extreme summer heat wave conditions for the years 1950, 1952, 1959, 1964, 1976, 1983, 1992, 1994, 1995, 2003 and 2006 are discussed for the Iberian Peninsula. The extreme summer heat wave years are taken from Vautard et al. [13]. Finally, in Section 3, a critical analysis is made for the two most recent extreme heat waves of 2003 and 2006. Heat wave conditions are computed using daily maximum temperatures from summer months as per the definition for heat waves prescribed by World Meteorological Organization. 


\subsection{Mean Maximum Temperature Analysis}

Observations indicate a concentric distribution of maximum temperatures with higher temperatures in the south. Temperature comparisons with observations indicate that the spatial distribution of seasonal mean maximum temperature is well represented by the model (Figure 2). The warmer temperatures over southern Iberian Peninsula and the colder regions along northern and north-eastern mountain ranges are well reproduced. Unlike in interpolated observations, the model shows the fine scale variations in temperatures related to location specific variations of surface/terrain variables. The regional variations in the mean maximum temperatures are well depicted by the model, which shows the advantages of using the high-resolution regional climate model. The smaller number of contours in observations could be because of less number of observations used in preparing E-OBS data. The differences in the seasonal mean maximum temperature between pre-industrial period (i.e. the period of 1950-1975), and the reference period (i.e. 1961-1990), as well as between post-industrial period (i.e. the period of 1976-2009) and reference period are computed for both model and observations. The changes in summer mean maximum temperatures before and during industrial period shows that at pre-industrial times, the change in summer seasonal maximum temperatures with respect to reference period in the model is almost negligible (Figure 2(c)), while some few regions over Iberian Peninsula seem (Figure 2(d)) to have increased its temperature up to $0.25^{\circ} \mathrm{C}$. This may be due to rapid urbanization process during this period that affected several regions of the globe along with Iberian Peninsula, a process that may not be well represented in the model due to the use of static land use datasets in the model domain. With the exception of these relatively small numbers of areas the model shows no change in temperature. We find that during post-industrial period the changes in temperatures are very significant in both model and observations (Figure 2(e) and Figure 2(f)). Simulation shows an increase of $0.25^{\circ} \mathrm{C}-0.50^{\circ} \mathrm{C}$ rise in temperature over the entire Iberian Peninsula with larger changes over the south and southeast part of Iberian Peninsula $\left(>0.5^{\circ} \mathrm{C}\right)$. In southern parts of the Iberian Peninsula and over Portugal region a temperature increase of $0.5^{\circ} \mathrm{C}$ is simulated. While model simulation is good over the southern parts, it underestimated the changes in maximum temperatures by $\sim 0.5{ }^{\circ} \mathrm{C}$ in the central and north-eastern regions.

An analysis of temperature changes in each month during pre- and post-industrial periods with respect to reference period are presented enabled us to explore departures from climate average conditions and study the heat waves in summer months. The analysis shows that while observations indicate a slight increase of $0.25^{\circ} \mathrm{C}$ in pre-industrial era in the month of June (Figure 3), those changes are negligible (Figure 3(a)). A large increase of temperature is noticed in the post-industrial period both in observations and simulations. Model temperature changes are about $0.25^{\circ} \mathrm{C}$ lower than the corresponding changes estimated from observations over entire Iberian region. A few exceptions are found over Lisbon and adjacent southern coastal regions. There is an increase of over $1^{\circ} \mathrm{C}$ over northern Spain and few selected regions in the south. The mountain regions and entire Mediterranean coast and northern coastal regions show an increase of $0.5^{\circ} \mathrm{C}$. Observations indicate that the entire Iberian region is showing an increase of $1^{\circ} \mathrm{C}$, except for some coastal regions and over some mountain regions that show an increase of $0.5^{\circ} \mathrm{C}$. In this analysis also it is very clear that the observations are more uniform way of increase in temperature and it is not showing changes on local to regional scale. This is because of the E-OBS data is of with $25 \mathrm{~km}$ grid resolution, where as the model is able to generate most of the regional features very well. Alternative high-resolution observations were unavailable at the time of this study for more comparisons.

Similar results to the June observation-simulation comparison are obtained when the month of July is examined. In July the mean maximum temperatures during pre-industrial period did not change in the model (Figure 4(a)) but some of the southern parts have increased about $0.5^{\circ} \mathrm{C}$ in observations (Figure 4 (c)). The rest of Iberia shows no change. In the post-industrial period, on the other hand, the mean maximum temperatures from the model (Figure 4(b)) and observations (Figure 4(d)) show a significant increase of $0.25^{\circ} \mathrm{C}$ to $1^{\circ} \mathrm{C}$. In the southern parts of the Iberian region the model results show an increase of $0.5^{\circ} \mathrm{C}$, which are well matches with observations. In northeast region, on the other hand, the observations show an increase of $0.75^{\circ} \mathrm{C}$ and, in some isolated pockets, an increase of $1^{\circ} \mathrm{C}$ that is not captured by model. Northern Portugal and adjoin regions with lower temperature and southern Iberian with higher temperature patterns are well represented by the model and with good agreement with observations. A difference of $\sim 0.25^{\circ} \mathrm{C}$ maximum temperature changes is noted between model and observations for July.

In August, the models show some coastal regions of Mediterranean and northern Iberian regions have a slight increase in temperature during the pre-industrial period (Figure 5(a)). A similar trend is noticed in the observations (Figure 5(c)), with a slight increase over Mediterranean coastal region and with no significant changes iden- 

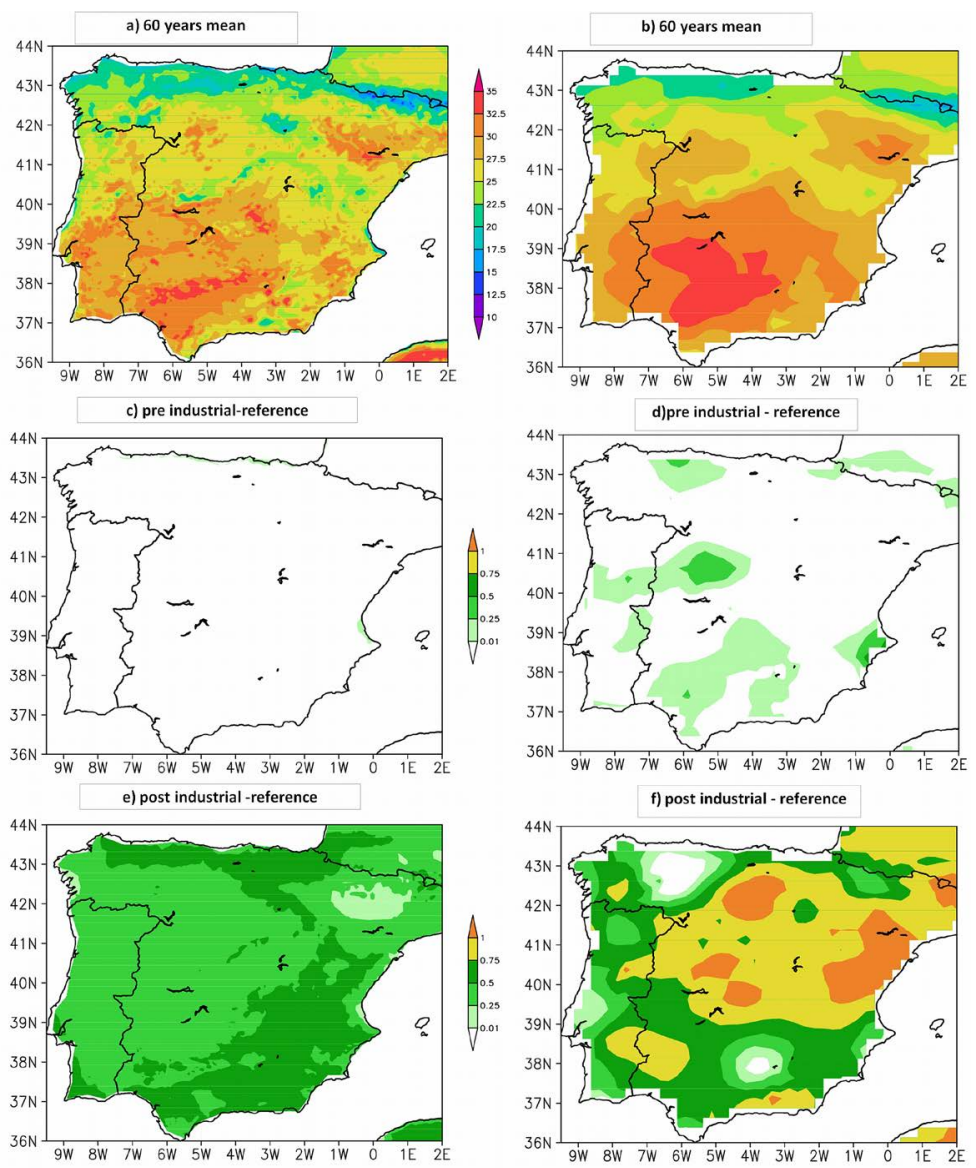

Figure 2. Mean seasonal maximum temperatures for 60-year period. Differences between mean seasonal maximum temperature for pre-industrial and post-industrial periods from the reference period (1961-1990). Left panel is for model and right panel is for observations.
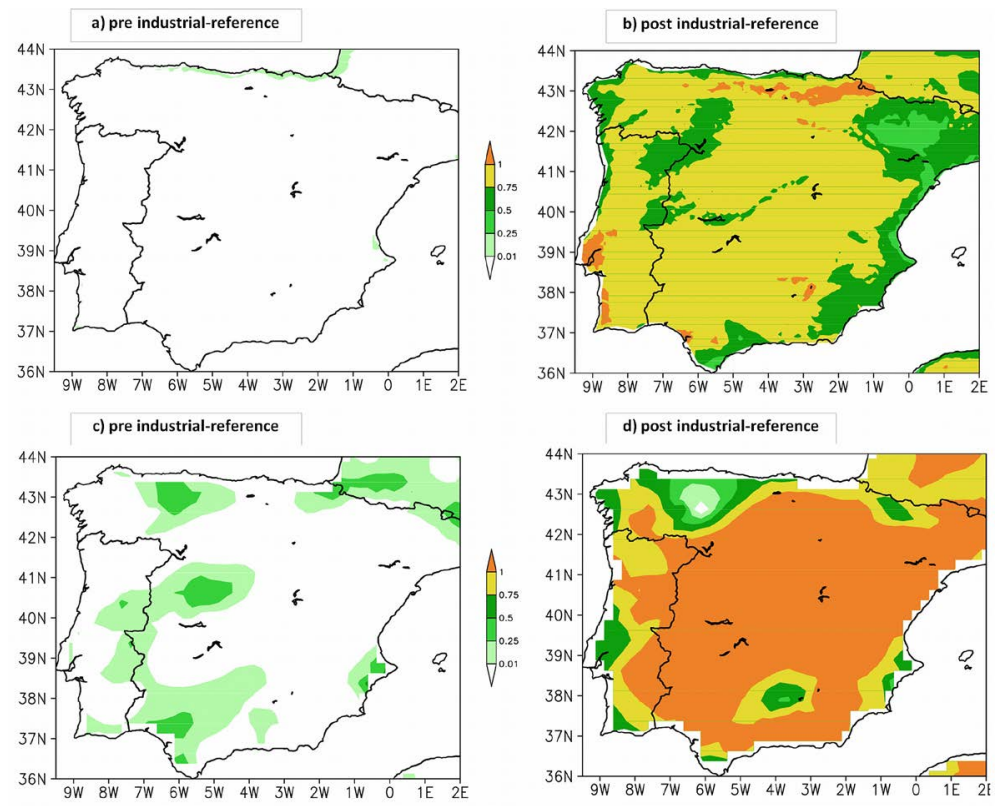

Figure 3. Differences between mean June month maximum temperature for pre-industrial and post-industrial periods from the reference period of 1961-1990. Top panel is for model and bottom panel is for observations. 

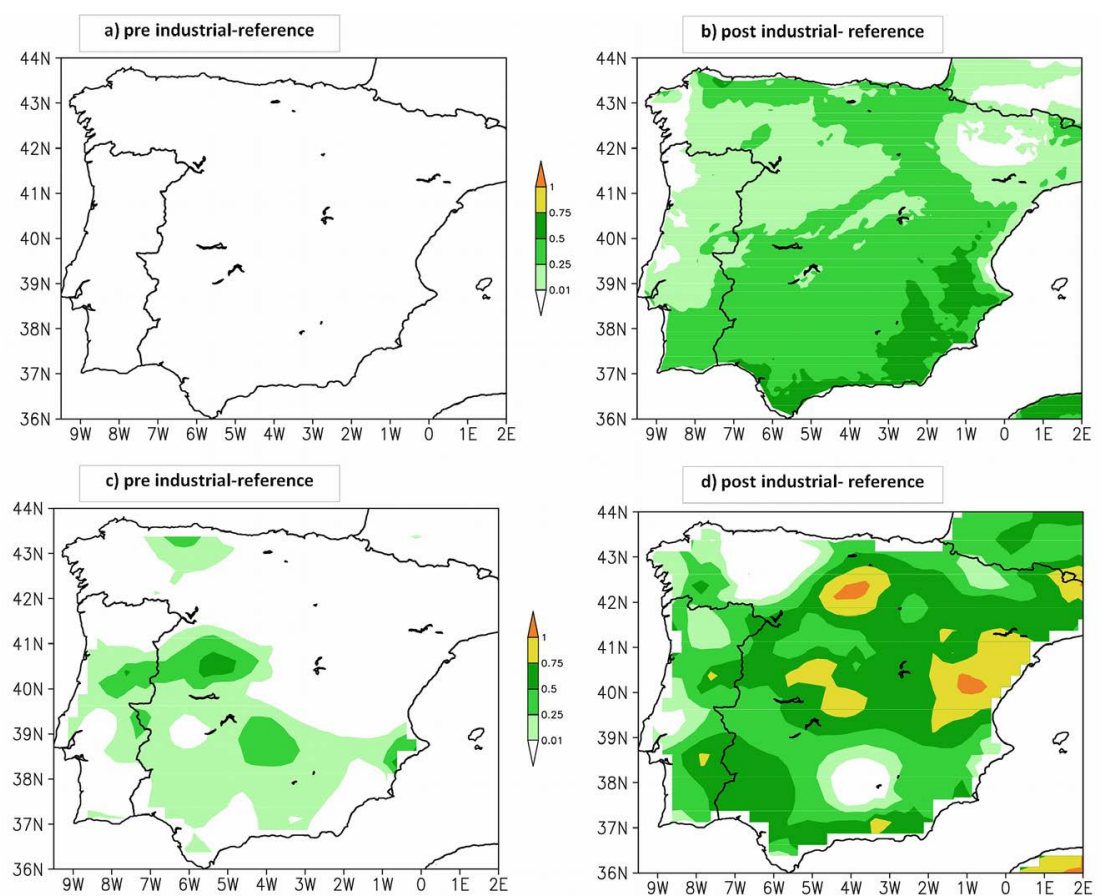

Figure 4. Differences between mean July month maximum temperature for pre-industrial and post-industrial periods from the reference period of 1961-1990. Top panel is for model and bottom panel is for observations.
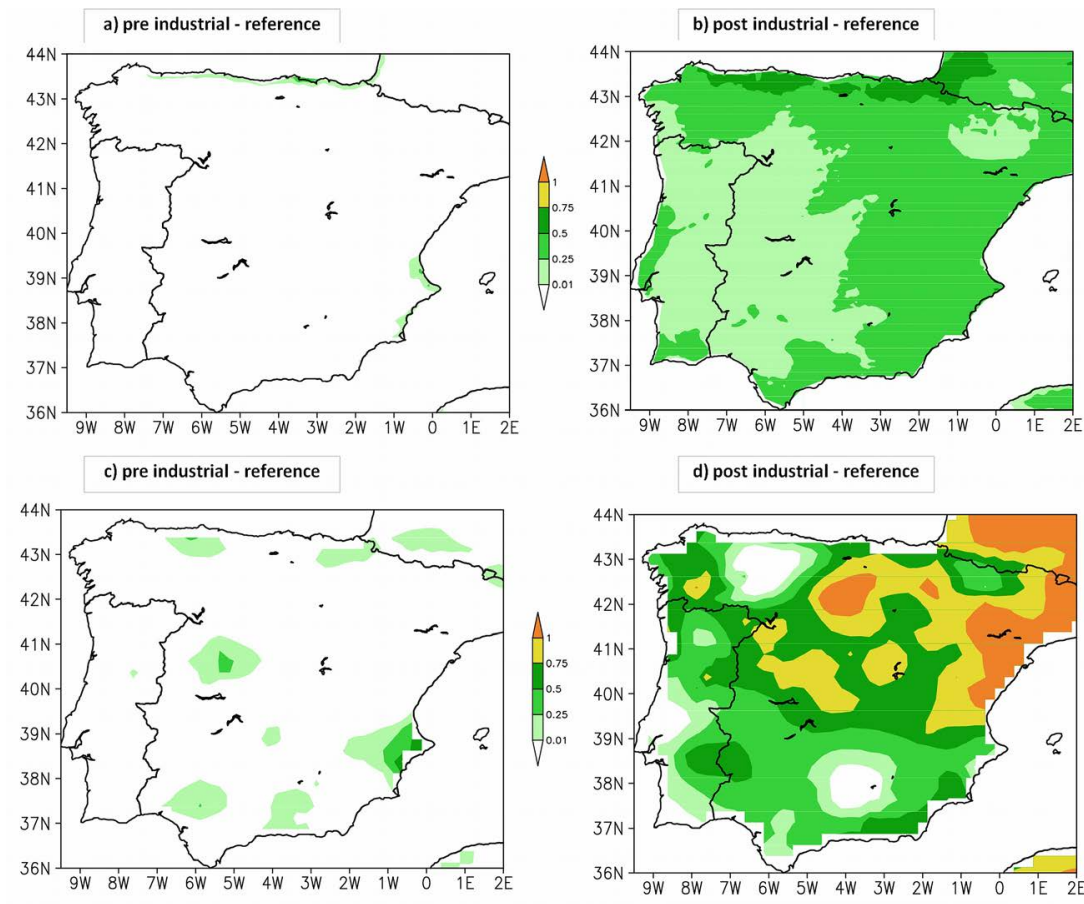

Figure 5. Differences between mean August month maximum temperature for pre-industrial and post-industrial periods from the reference period of 1961-1990. Top panel is for model and bottom panel is for observations.

tified in the rest of the whole Iberian. In contrast to the pre-industrial era, the post-industrial period shows a temperature increase in (Figure 5(b) and Figure 5(d)) south and south-eastern parts of Iberia in both simulations and observations. The increase is noticed in both model and observations from southern Portugal and southwestern Iberia, towards north and north eastern Iberia. The increase is in the range of $0.25^{\circ} \mathrm{C}$ to $0.5^{\circ} \mathrm{C}$ in the 
model where and of $0.25^{\circ} \mathrm{C}$ to $1^{\circ} \mathrm{C}$ in observations. The model underestimates for an amount of $0.25^{\circ} \mathrm{C}$ to $0.5^{\circ} \mathrm{C}$ from south to north and north-eastern region.

\subsection{Mean Maximum Temperature Analysis for Extremely Heat Wave Years}

Next we examine 11 years of severe heat waves between 1950-2009. This 60 years period was chosen based on a previous study by Vautard et al. [13] that identified 10 extreme summer heat wave conditions during the same period. The heat waves occurred in 1950, 1952, 1959, 1964, 1976, 1983, 1992, 1994, 1995 and 2003. We also added the recent heat wave of 2006. These 11 years are used to identify the abnormal changes in temperatures that occurred in comparison with reference period. For this analysis we used the monthly mean maximum temperatures for both model and observations.

The model shows a very clear increase in temperature, with significant regional changes, for June monthly mean temperatures in the 11-year period with severe heat waves (Figure 6(a)). The model shows more than $32.5^{\circ} \mathrm{C}$ over many parts of the southern and some north-eastern parts of Iberian Peninsula. A good pattern comparison is found in ARW simulation for the extreme year summer temperatures as in observations. The observations show (Figure 6(b)) that the temperatures are around $30^{\circ} \mathrm{C}$ in southern parts and are still low in north-eastern part of Iberian Peninsula. Interestingly, the model shows very fine scale regional temperature patterns that are not identifiable from interpolated observations. The change in mean heat wave June maximum temperatures is quite significant in both model and observations (Figure 6(c) and Figure 6(d)) with regard to reference period. The change of $0.5^{\circ} \mathrm{C}$ to $2^{\circ} \mathrm{C}$ is noticed in both model and observations although with spatial variability. In the model, there is an increase of $2^{\circ} \mathrm{C}$ over Lisbon region, about $1^{\circ} \mathrm{C}$ over south of Portugal, $1.5^{\circ} \mathrm{C}$ over and north of Portugal and about $1^{\circ} \mathrm{C}$ to $1.5^{\circ} \mathrm{C}$ towards north and northeastern Iberia. In the south of the Iberian Peninsula the model temperature changes are about $0.01^{\circ} \mathrm{C}$ to $0.5^{\circ} \mathrm{C}$. In observations, the increasing trend from southern Portugal to north and north-eastern Iberian Peninsula matches well the model but with an intensity of about $0.5^{\circ} \mathrm{C}$ higher. Observations show that almost all of the Southern and north-eastern Iberian Peninsula has increased by $1^{\circ} \mathrm{C}$ to $1.5^{\circ} \mathrm{C}$ and north eastern parts by $1.5^{\circ} \mathrm{C}$ to $2^{\circ} \mathrm{C}$. Mean temperatures in July have increased more than those of the previous month, as it is expected, in both model and observations (Figure 7(a) and Figure 7(b)). Mean temperatures of more than $35^{\circ} \mathrm{C}$ are noticed in both model and observations but in the model, clear regional changes at local scales are apparent. The change in temperatures from the reference period shows a clear increasing trend from the south-west to the north-east of the Iberian Peninsula in both model and observations. The range of increase is of about $0.01^{\circ} \mathrm{C}$ to $1^{\circ} \mathrm{C}$ in the model while it is $0.01^{\circ} \mathrm{C}$ to $1.5^{\circ} \mathrm{C}$ in the observations. A similar pattern as in July is noticed in August in both model and observations, with slightly lower intensity in mean severe summer temperatures (Figure 8(a) and Figure 8(b)) and with lesser changes in temperatures (Figure 8(c) and Figure 8(d)) with respect to the reference period. These results show that while the extreme high temperatures in Iberian Peninsula are found in July, June temperatures are the ones that increased the most in the season of JJA. That is very clear from the changes in both 60-year mean maximum temperatures and extreme heat wave mean June temperatures with respect to the reference period. In July and August, the magnitude of changes is than in June. June changes are higher in the south of Portugal and north-western Iberia and in the other two months the shift moves towards north and north eastern parts of Iberian Peninsula. This phenomenon matches well the observations. It is very clear in model results that there are large changes in extreme temperatures in Iberian Peninsula, particularly in the southern parts and in June and moving towards north-eastern parts of Iberia in July and August. These fine features are not noticeable with the observations probably because of the number of observations considered in preparing the E-OBS data. The fine scale features are well noticed in the model because of the advantage of using a high resolution RCM. The increase of temperature changes over north-eastern parts of Iberian Peninsula may be because of heat advection due to anticyclonic circulations, significant changes of landuse/vegetation which may influence by changing albedo, emissivity factors and rapid urbanization.

\subsection{Mean Maximum Temperature Analysis of the Latest Heat Wave Years (2003 and 2006)}

We used 10-day daily maximum mean temperatures for both 2003 and 2006 to understand the duration of heat waves. In 2003 (Figure 9), the heat wave conditions were detected from 10th of June onwards extending to the last week of the month. The total duration was of about 15 to 20 days and it was noticed in almost all areas of Iberian Peninsula except the northern parts. After a 10-day gap a second spell became apparent from 10-20 July in most of 

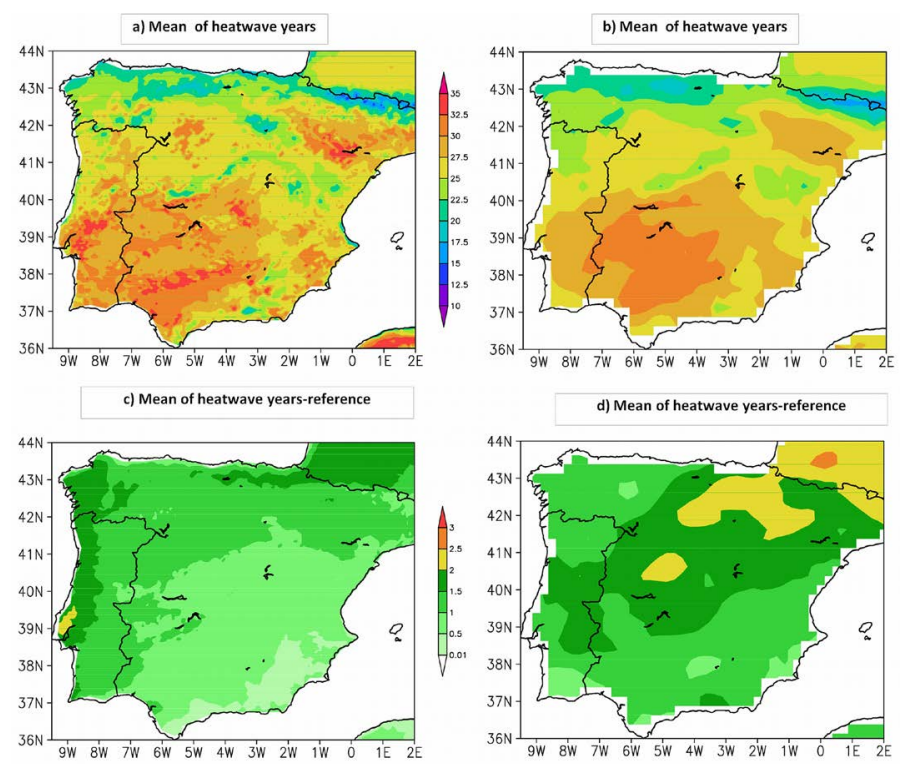

Figure 6. Mean June month maximum temperatures for extreme heat wave years (top panel). Differences between mean June month maximum temperatures for extreme heat wave years from the reference period of 1961-1990 (bottom panel). Left panel is for model and right panel is for observations.
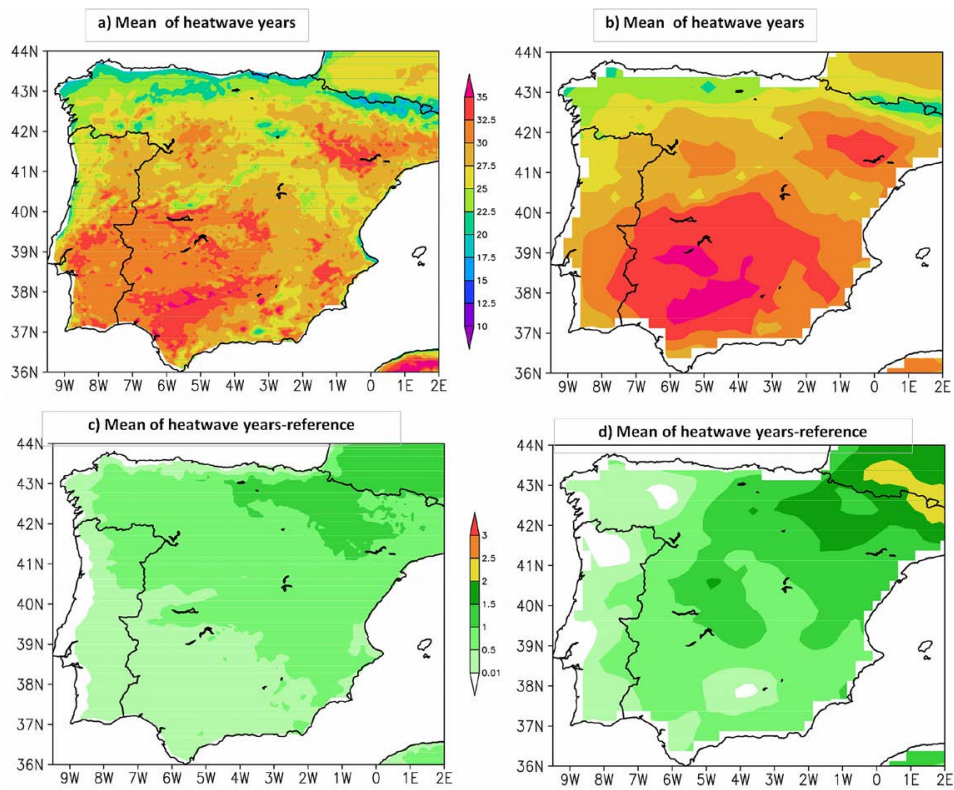

Figure 7. Mean July month maximum temperatures for extreme heat wave years (top panel). Differences between mean July month maximum temperatures for extreme heat wave years from the reference period of 1961-1990 (bottom panel). Left panel is for model and right panel is for observations.

the southern parts of the Iberian region and it moved still further south for another 10 days; after that it spread over the entire Iberian Peninsula. The heat wave conditions persisted over nearly 50 days with small gaps starting from second week of July to the last week of August. Because of the length of this severe heat wave conditions over Iberian region, several heat-wave related deaths and forest fires were reported over the region. In 2006 heat wave conditions were not very apparent in June. Mostly, heat wave conditions prevailed from 10 July over the south-west of the Iberian Peninsula and they slowly extended to the north-eastern parts of Iberian Peninsula by end of July with increased intensity. The mean temperatures reached almost $40^{\circ} \mathrm{C}$ and the severity of the heat wave (Figure 10) was much higher (by $\sim 5^{\circ} \mathrm{C}$ ) than that of 2003. But the duration of heat wave conditions in 2006 were 

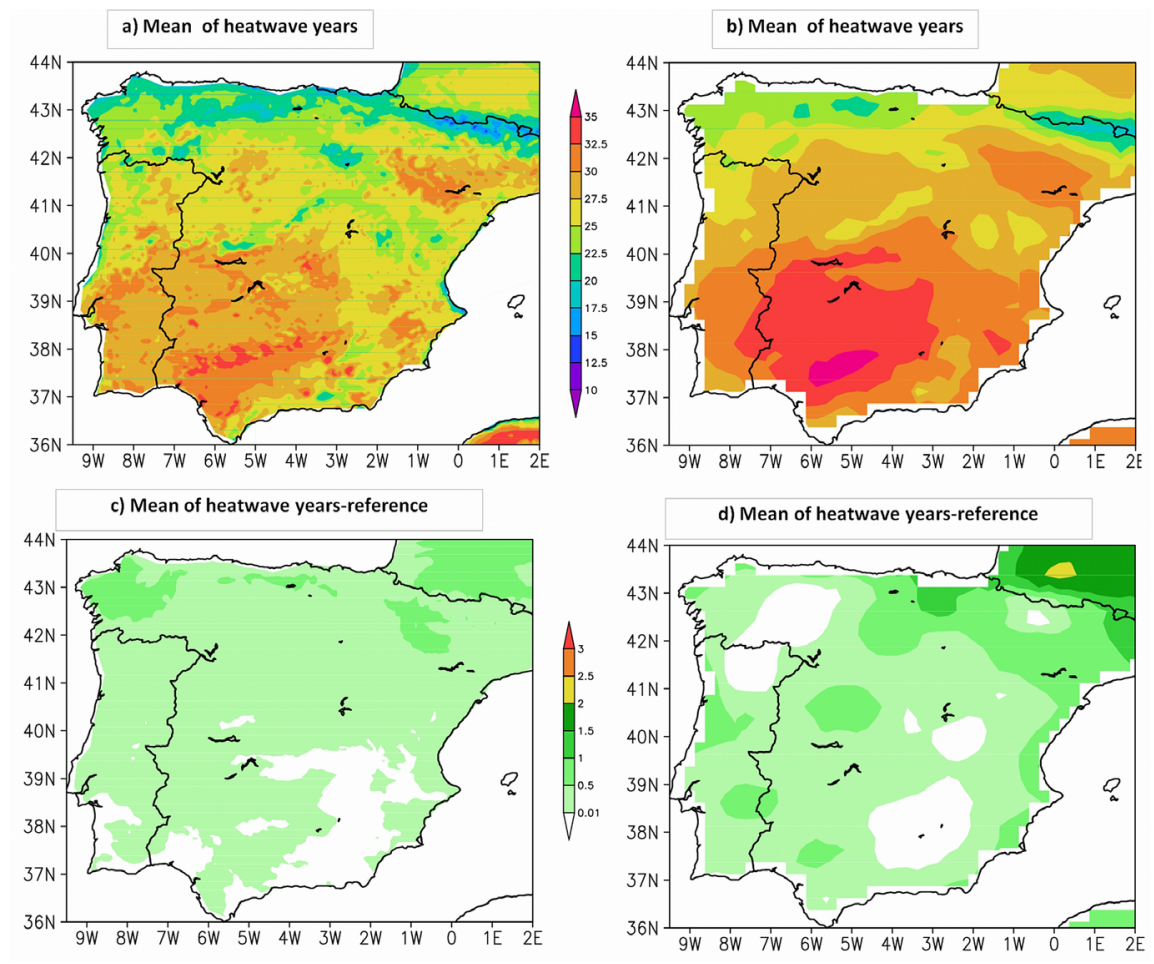

Figure 8. Mean August month maximum temperatures for extremely heat wave years (top panel). Differences between mean August month maximum temperatures for extremely heat wave years from the reference period of 1961-1990 (bottom panel). Left panel is for model and right panel is for observations.

of about 25 days starting from the second week of July to the first week of August, while that of 2003 lasted for nearly 50 days. The heat wave temperatures were much higher in 2006 than in 2003 over the southern parts of Iberian Peninsula. There were two continuous spells of heat wave conditions in 2003, one in June and the other one in July while in 2006 one continuous spell of heat wave from second week of July prevailed.

\section{Summary}

The ARW model is used to simulate the regional heat wave conditions over the Iberian Peninsula related to extreme maximum temperatures over a 60-year climate period. A RCM is used at a high spatial and temporal resolution ( $5 \mathrm{~km}, 1$ hour) and model temperature climate is compared with the E-OBS data set. The analysis of the maximum temperatures is made over summer season (June-August) considering the reference period 19611990 with breakups of pre and post industrial eras to identify the corresponding temperature changes. The results indicate that the temperatures have significantly increased in the post industrial era, which agrees with results reported in many other studies. The summer mean maximum temperatures increased about $0.5^{\circ} \mathrm{C}$ after industrialization over most parts of Europe which agrees with the observations. Temperature changes are larger in June than in July and August. The June month temperatures increased by $1^{\circ} \mathrm{C}-1.5^{\circ} \mathrm{C}$ over most parts of the Iberian Peninsula whereas July and August temperatures increased by $0.25^{\circ} \mathrm{C}-0.75^{\circ} \mathrm{C}$. These model results reasonably agree with observations, which are spatially smooth due to interpolation of sparse point data sets. The model realistically simulated the fine scale summer temperature changes over the entire Iberian Peninsula.

Extreme heat waves of 11 years are chosen during this 60-year period to understand the model capability to simulate extreme hot conditions. The 11-year mean seasonal heat wave conditions are well simulated by the model and with good agreement. The propagation of severe hot condition towards the north western region of Iberian Peninsula as in observations is well simulated by model. An increase is of $0.5^{\circ} \mathrm{C}$ to $2^{\circ} \mathrm{C}$ in both model and in observations is found over the study domain. Especially the increase of temperatures in June indicating extreme heat wave conditions over north eastern parts of Iberian region relative to July and August is well produced by model. Analysis of various parameters shows that the model captured the mean heat wave conditions found in 
a) 1-10 June, 2003

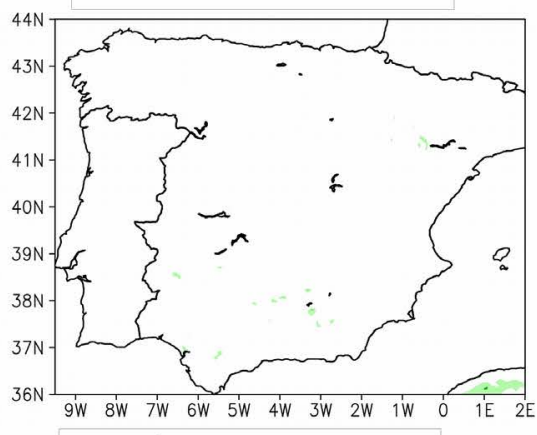

c) 20-30 June, 2003

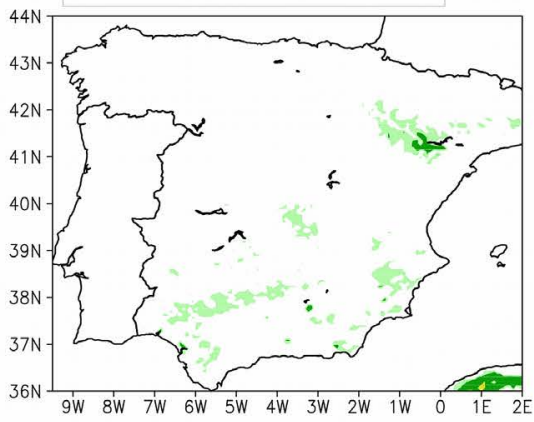

e) 10-20 July, 2003

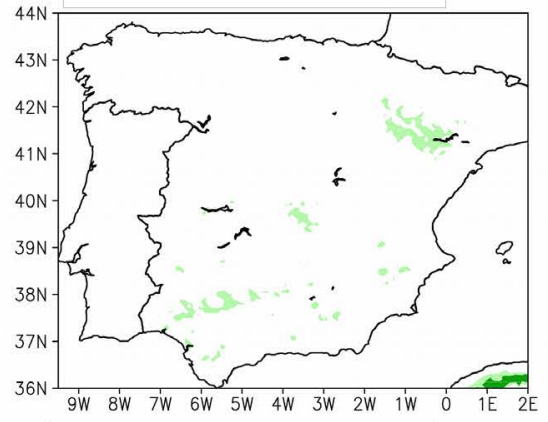

g) 1-10 August, 2003

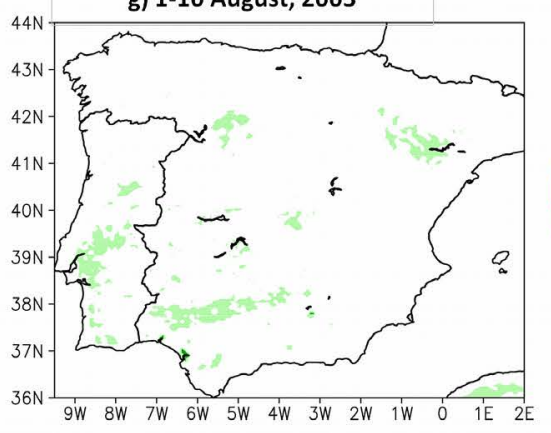

b) $10-20$ June, 2003

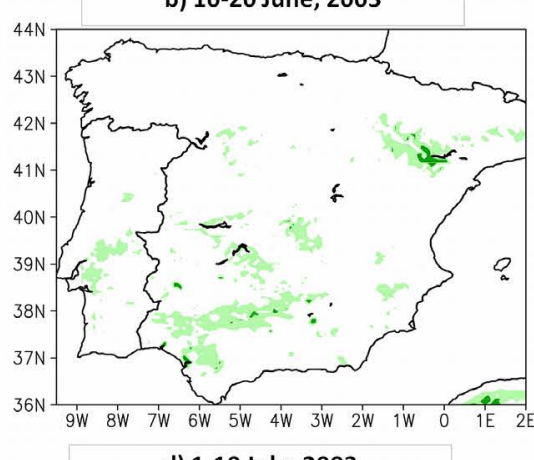

d) 1-10 July, 2003
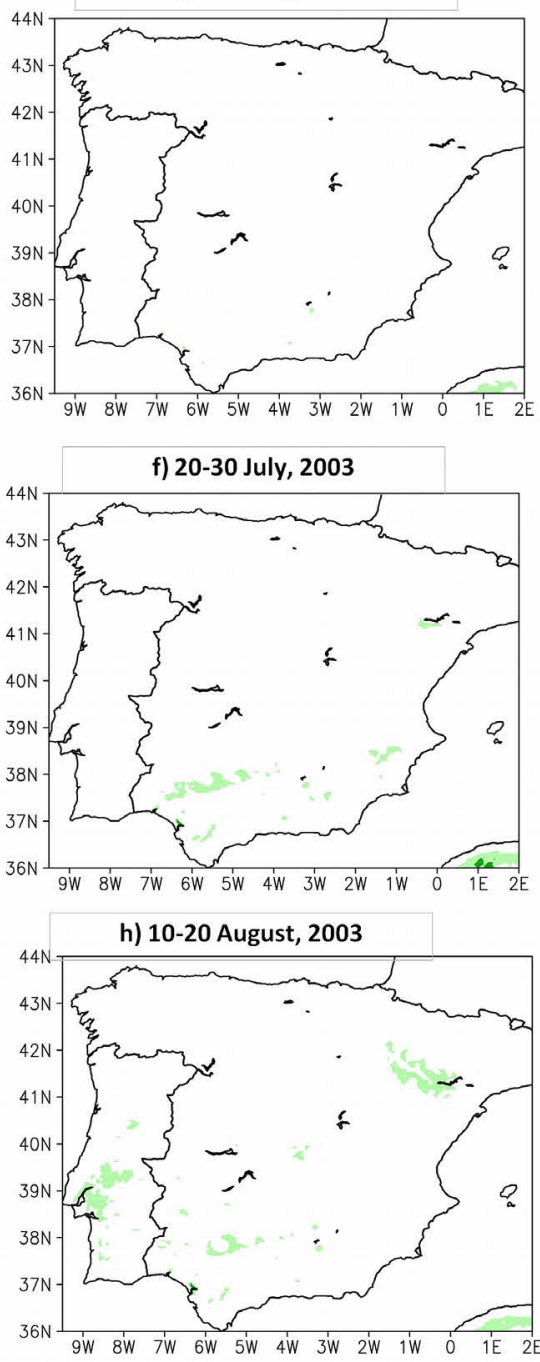

Figure 9. Model produced 10-day mean maximum temperatures for 2003 summer (more than $35^{\circ} \mathrm{C}$ only plotted).

E-OBS observations. Analysis of two extreme years indicated that the heat wave of 2003 has two spells one in June and other one in July. The total length of these heat conditions sustained for about 50 days with mean maximum temperatures of more than $40^{\circ} \mathrm{C}$. In 2006, the heat wave conditions persisted for about 25 days starting in the beginning of the second week of July. The model simulated the higher intensive heat wave conditions in 2006 relative to 2003 in agreement with observations. The progress of heat wave conditions from south western 
a) 1-10 June, 2006

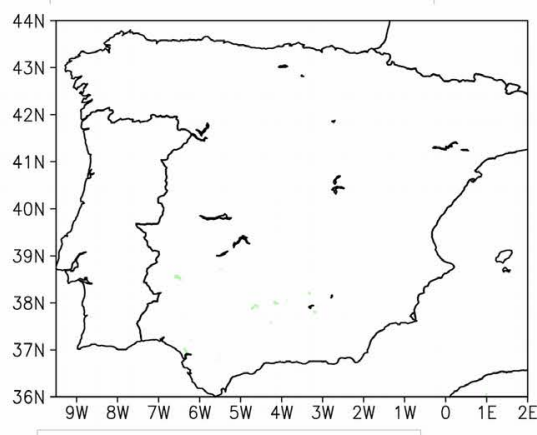

c) 20-30 June, 2006

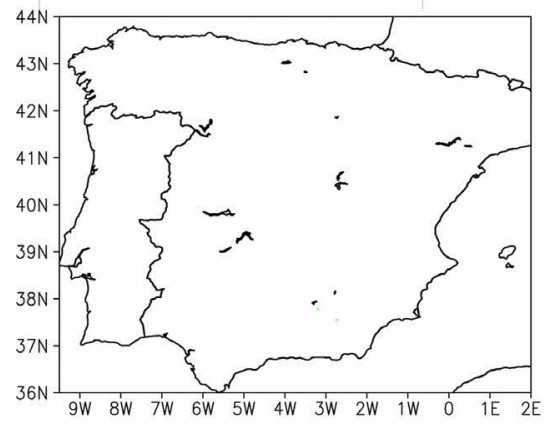

e) 10-20 July, 2006

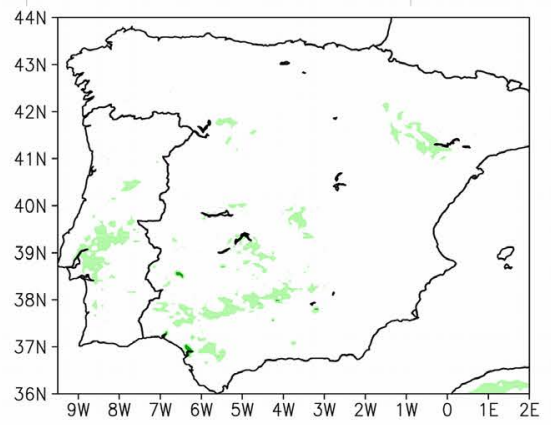

g) 1-10 August, 2006

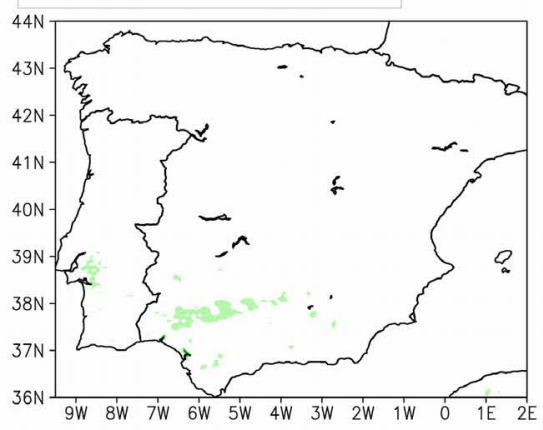

b) 10-20 June, 2006

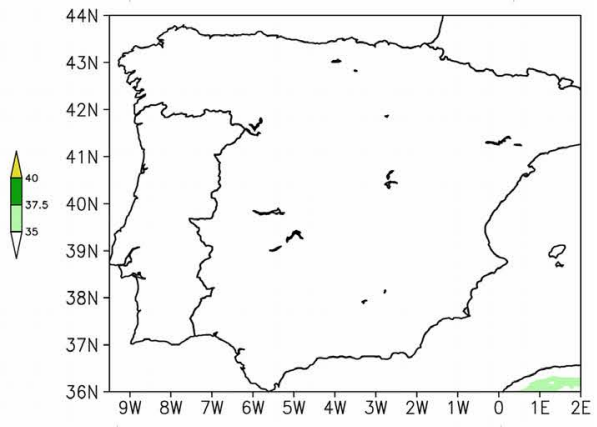

d) 1-10 July, 2006
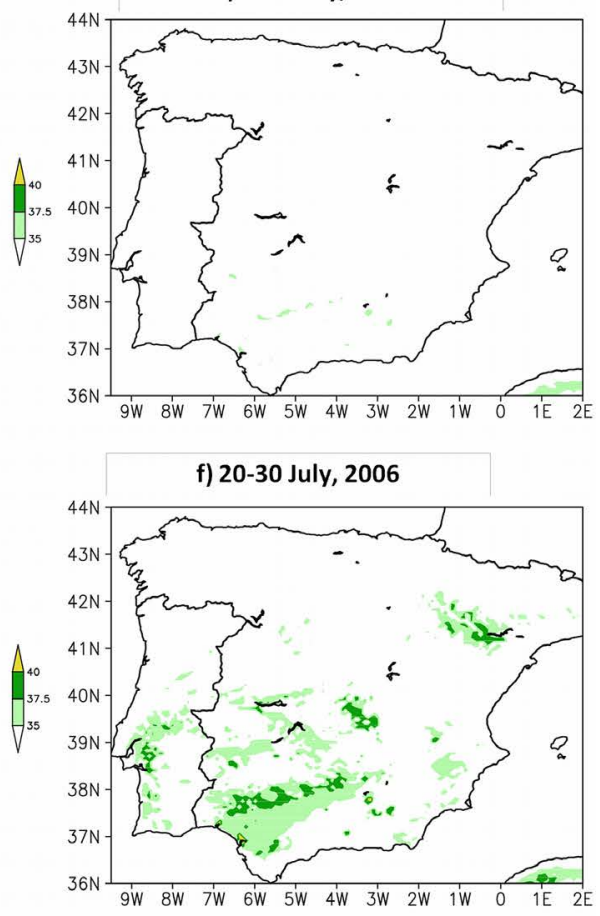

h) 10-20 August, 2006

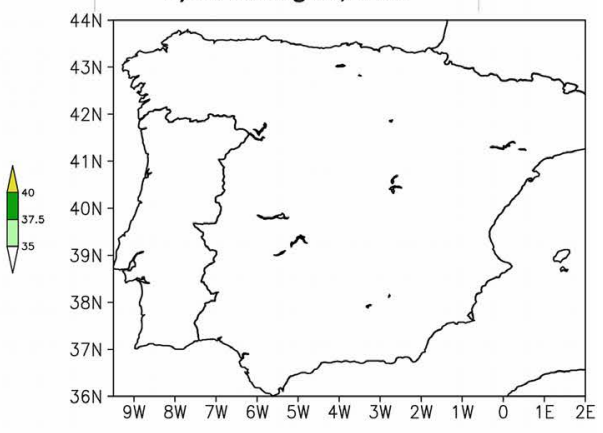

Figure 10. Model produced 10 day mean maximum temperatures for 2006 summer (more than $35^{\circ} \mathrm{C}$ only plotted).

parts to north eastern parts of Iberian region is well produced by the model.

\section{Acknowledgements}

This work was funded through the Integrated Program of IC \& DT Call No. 1/SAESCTN/ALENT-07-0224-FEDER- 
001755. Hari Prasad also acknowledges funding by the Geophysics Centre, University of Évora, Portugal, under the contract with Portuguese FCT, and PEst-OE/CTE/UI0078/2011. The authors gratefully acknowledge the NCAR, USA for the public access of WRF-ARW mesoscale model, NCEP/NCAR USA for the reanalysis data sets used in the study. We also acknowledge the E-OBS dataset from the EU-FP6 project ENSEMBLES for making it available for use in this study. The authors thank the super computational facility CESGA, Galicia Supercomputing Centre, Spain (http://www.cesga.es/) for allowing us to carry out the experiments there.

\section{References}

[1] Schär, C., Vidale, P.L., Lüthi, D., Frei, C., Häberli, C., Liniger, M.A. and Appenzeller, C. (2004) The Role of Increasing Temperature Variability in European Summer Heatwaves. Nature, 427, 332-336. http://dx.doi.org/10.1038/nature02300

[2] Beniston, M. (2004) The 2003 Heat Wave in Europe: A Shape of Things to Come? An Analysis Based on Swiss Climatological Data and Model Simulations. Geophysical Research Letters, 31, Article ID: L02202. http://dx.doi.org/10.1029/2003GL018857

[3] Intergovernmental Pane (2004) The Physical Science Basis. Working Group I Contribution to the Fourth Assessment Report of the IPCC-Intergovernmental Panel on Climate Change. Cambridge University Press, New York.

[4] Benestad, R.E. (2005) Climate Change Scenarios for Northern Europe from Multi-Model IPCC AR4 Climate Simulations. Geophysical Research Letters, 32, Article ID: L17704. http://dx.doi.org/10.1029/2005GL023401

[5] Tebaldi, C., Hayhoe, K., Arblaster, J.M. and Meehl, G.E. (2006) Going to the Extremes: An Intercomparison of Model-Simulated Historical and Future Changes in Extreme Events. Climatic Change, 79, 185-211. http://dx.doi.org/10.1007/s10584-006-9051-4

[6] Cassou, C., Terray, L. and Phillips, A.S. (2005) Tropical Atlantic Influence on European Heat Waves. Journal of Climate, 18, 2805-2811.

[7] Della-Marta, P.M. andWanner, H. (2006) A Method of Homogenising the Extremes and Mean of Daily Temperature Measurements. Journal of Climate, 19, 4179-4197. http://dx.doi.org/10.1175/JCLI3855.1

[8] Rebetez, M., Dupont, O. and Giroud, M. (2008) An Analysis of the July 2006 Heatwave Extent in Europe Compared to the Record Year of 2003. Theoretical and Applied Climatology, 95, 1-7. http://dx.doi.org/10.1007/s00704-007-0370-9

[9] Fischer, E.M., Seneviratne, S.I., Luthi, D. and Schaer, C. (2007) Contribution of Land-Atmosphere Coupling to Recent European Summer Heat Waves. Geophysical Research Letters, 34, Article ID: L06707. http://dx.doi.org/10.1029/2006GL029068

[10] Fischer, E.M., Seneviratne, S.I., Vidale, P.L., Luthi, D. and Schaer, C. (2007) Soil Moisture-Atmosphere Interactions during the 2003 European Summer Heat Wave. Journal of Climate, 20, 5081-5099. http://dx.doi.org/10.1175/JCLI4288.1

[11] Ferranti, L. and Viterbo, P. (2006) The European Summer of 2003: Sensitivity to Soil Water Initial Conditions. Journal of Climate, 19, 3659-3680. http://dx.doi.org/10.1175/JCLI3810.1

[12] D’Andrea, F., Provenzale, A., Vautard, R. and De Noblet-Decoudré, N. (2006) Hot and Cool Summers: Multiple Equilibria of the Continental Water Cycle. Geophysical Research Letters, 33, Article ID: L24807. http://dx.doi.org/10.1029/2006GL027972

[13] Vautard, R., et al. (2007) Summertime European Heat and Drought Waves Induced by Wintertime Mediterranean Rainfall Deficit. Geophysical Research Letters, 34, Article ID: L07711.

[14] Giorgi, F. and Bates, G. (1989) The Climatological Skill of a Regional Model over Complex Terrain. Monthly Weather Review, 117, 2325-2347. http://dx.doi.org/10.1175/1520-0493(1989)117<2325:TCSOAR>2.0.CO;2

[15] Bhaskaran, B., Jones, R.G., Murphy, J.M. and Noguer, M. (1996) Simulation of the Indian Summer Monsoon Using a Nested Regional Climate Model: Domain Size Experiments. Climate Dynamics, 12, 573-578. http://dx.doi.org/10.1007/BF00216267

[16] McGregor, J.L. (1997) Regional Climate Modeling. Meteorology and Atmospheric Physics, 63, 105-117. http://dx.doi.org/10.1007/BF01025367

[17] de Castro, M., Gallardo, C., Jylha, K. and Tuomenvirta, H. (2007) The Use of a Climate-Type Classification for Assessing Climate Change Effects in Europe from an Ensemble of Nine Regional Climate Models. Climatic Change, 81, 329-341. http://dx.doi.org/10.1007/s10584-006-9224-1

[18] Heikkilä, U., Sandvik, A. and Sorterberg, A. (2010) Dynamical Downscaling of ERA-40 in Complex Terrain Using WRF Regional Climate Model. Climate Dynamics, 36, 845-866. http://dx.doi.org/10.1007/s00382-010-0928-6

[19] Hari Prasad, D., Wibig, J. and Repaz, M. (2010) Numerical Modeling of the Severe Cold Weather Event over Central 
Europe (January 2006). Advances in Meteorology, 2010, Article ID: 619478.

[20] Hari Prasad, D, Venkata Srinivas, C., Venkata Bhaskar Rao, D. and Anjaneyulu, Y. (2011) Simulation of Indian Monsoon Extreme Rainfall Events during the Decadal Period 2000-2009 Using a High Resolution Mesoscale Model. Advances in Geosciences, A6, 31-48.

[21] Hari Prasad, D., Salgado, R., Perdigao, J. and Venkata Srinivas, C. (2014) A Regional Climate Simulation Study Using WRFARW Model over Europe and Evaluation for Extreme Temperature Weather Events. International Journal of Atmospheric Sciences, 2014, Article ID: 704079. http://dx.doi.org/10.1155/2014/704079

[22] Li, J.F., Zhang, Q., Chen, Y.Q.D. and Singh, V.P. (2013) GCMs-Based Spatiotemporal Evolution of Climate Extremes during the 21st Century in China. Journal of Geophysical Research, 118, 11017-11035.

[23] Nikulin, G., Kjellström, E., Hansson, U., Strandberg, G. and Ullerstig, A. (2011) Evaluation and Future Projections of Temperature, Precipitation and Wind Extremes over Europe in an Ensemble of Regional Climate Simulations. Tellus, 63, 41-55. http://dx.doi.org/10.1111/j.1600-0870.2010.00466.x

[24] Lorenz, P. and Jacob, D. (2010) Validation of Temperature Trends in the ENSEMBLES Regional Climate Model Runs Driven by ERA40. Climate Research, 44, 167-177.

[25] Rummukainen, M. (2010) State-of-the-Art with Regional Climate Models. Vol. 1, John Wiley \& Sons, Hoboken, 8296.

[26] Kjellström, E., Boberg, F., Castro, M., Christensen, H.J., Nikulin, G. and Sánchez, E. (2010) Daily and Monthly Temperature and Precipitation Statistics as Performance Indicators for Regional Climate Models. Climate Research, 44, 135-150.

[27] Srinivas, C.V., Hari Prasad, D., Venkata Bhaskar Rao, D., Anjaneyulu, Y., Baskaran, R. and Venkatraman, B. (2012) Simulation of the Indian Summer Monsoon Regional Climate Using Advanced Research WRF Model. International Journal of Climatology, 33, 1195-1210. http://dx.doi.org/10.1002/joc.3505

[28] Srinivas, C.V., Bhaskar Rao, D.V., Hari Prasad, D., Hari Prasad, K.B.R.R., Baskaran, R. and Venkatraman, B. (2014) A Study on the Influence of the Land Surface Processes on the Southwest Monsoon Simulations Using a Regional Climate Model. Pure and Applied Geophysics, in Press. http://dx.doi.org/10.1007/s00024-014-0905-9

[29] Skamarock, W.C., Klemp, J.B., Dudhia, J., Gill, D.O., Barker, D.M., Duda, M.G., Huang, X.-Y., Wang, W. and Powers, J.G. (2008) A Description of the Advanced Research WRF Version 3. NCAR Technical Note, NCAR/TN-475+ STR. Mesoscale and Microscale Meteorology Division, National Center for Atmospheric Research, Boulder.

[30] Kalnay, E., Kanamitsu, M., Kistler, R., et al. (1996) The NCEP/NCAR 40-Year Reanalysis Project. Bulletin of the American Meteorological Society, 77, 437-471. http://dx.doi.org/10.1175/1520-0477(1996)077<0437:TNYRP>2.0.CO;2

[31] Araújo, M.B., Ferri-Yáñez, F., Bozinovic, F., Marquet, P.A., Valladares, F. and Chown, S.L. (2013) Heat Freezes Niche Evolution. Ecology Letters, 16, 1206-1219. http://dx.doi.org/10.1111/ele.12155

[32] Haylock, M., Hofstra, N., Klein-Tank, A., Klok, E.J., Jones, P. and New, M. (2008) A European Daily High-Resolution Gridded Data Set of Surface Temperature and Precipitation for 1950-2006. Journal of Geophysical Research: Atmospheres, 113, D20119. http://dx.doi.org/10.1029/2008JD010201

[33] Soares, P.M.M., Cardoso, R.M., Miranda, P.M.A., Viterbo, P. and Belo-Pereira, M. (2012) Assessment of the ENSEMBLES Regional Climate Models in the Representation of Precipitation Variability and Extremes over Portugal. Journal of Geophysical Research, 117, Article ID: D07114. http://dx.doi.org/10.1029/2011JD016768 
Scientific Research Publishing (SCIRP) is one of the largest Open Access journal publishers. It is currently publishing more than 200 open access, online, peer-reviewed journals covering a wide range of academic disciplines. SCIRP serves the worldwide academic communities and contributes to the progress and application of science with its publication.

Other selected journals from SCIRP are listed as below. Submit your manuscript to us via either submit@scirp.org or Online Submission Portal.
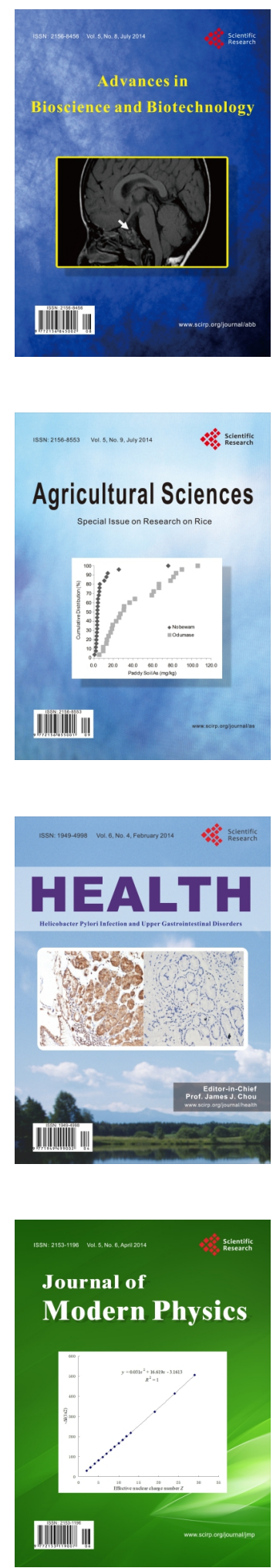
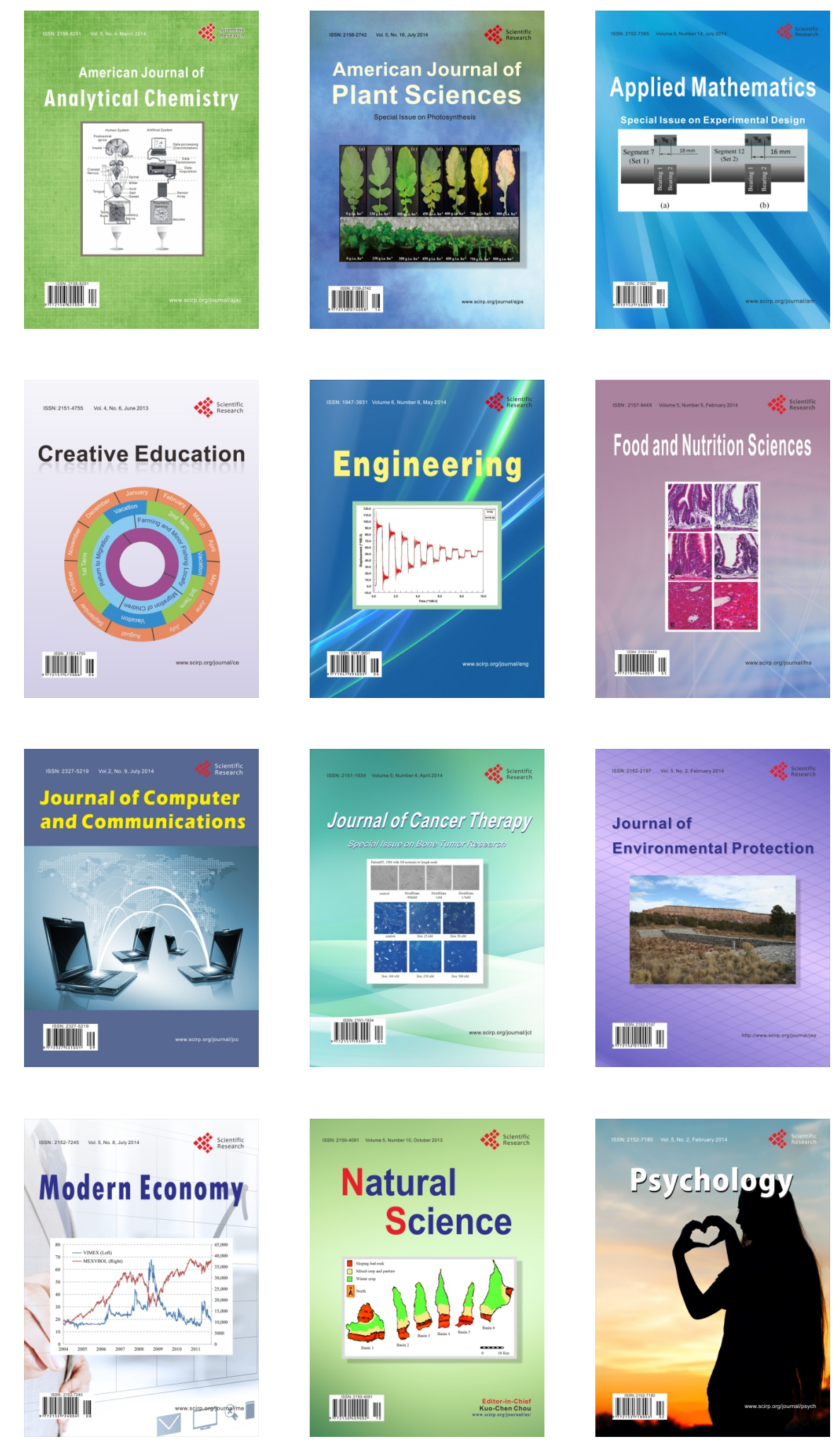